\title{
Postanaesthetic shivering - from pathophysiology to prevention
}

\author{
Maria Bermudez Lopez
}

Department of Anaesthesiology, Intensive Care Medicine and Pain Medicine, Clinic of Anaesthesia, University Hospital of Lucus Augusti, Lugo, Spain

\begin{abstract}
Postoperative shivering is a common complication of anaesthesia. Shivering is believed to increase oxygen consumption, increase the risk of hypoxemia, induce lactic acidosis, and catecholamine release. Therefore, it might increase the postoperative complications especially in high-risk patients. Moreover, shivering is one of the leading causes of discomfort for postsurgical patients.

Shivering is usually triggered by hypothermia. However, it occurs even in normothermic patients during the perioperative period. The aetiology of shivering has been understood insufficiently. Another potential mechanism is pain and acute opioid withdrawal (especially with the use of short-acting narcotics). Besides that shivering is poorly understood, the gold standard for the treatment and prevention has not been defined yet. Perioperative hypothermia prevention is the first method to avoid shivering. Many therapeutic strategies for treating shivering exist and most are empiric. Unfortunately, the overall quality of the antishivering guidelines is low. Two main strategies are available: pharmacological and non-pharmacological antishivering methods. The combination of forced-air warming devices and intravenous meperidine is the most validated method. We also analysed different medications but final conclusion about the optimal antishivering medication is difficult to be drawn due to the lack of high-quality evidence.

Nevertheless, control of PS is possible and clinically effective with simple pharmacological interventions combined with non pharmacological methods.

However, to be consistent with the most up-to-date, evidence-based practice, future antishivering treatment protocols should optimize methodological rigor and transparency.

Keywords: postoperative shivering, postanaesthetic complications, hypothermia
\end{abstract}

\section{Introduction}

Postoperative shivering is a frequent complication of anaesthesia; it has been reported to range from 20 to $70 \%$ in general anaesthesia [1]. Shivering is believed to increase oxygen consumption and increase the risk of hypoxemia; it might also increase postoperative complications. Shivering is usually triggered by hypothermia. However, it occurs even in normothermic patients during the perioperative period. The aetiology of shivering is not understood sufficiently [2]. In addition to the fact that shivering is poorly understood, the gold standard for the treatment and prevention has not been defined yet. Because of its importance as a postoperative complication and the lack of evidence about aetiology and treatment, this narrative review of the published literature on this topic is necessary. Shivering, a syndrome involving involuntary oscillatory contractions of skeletal muscles, is a common and challenging side effect of anaesthesia and targeted temperature modulation [3]. Shivering is a physiologic response to cold exposure and the body's next step in heat preservation after peripheral vasoconstriction [4]. Postoperative shivering (PS) is an involuntary, oscillatory muscular activity during early recovery after anaesthesia. Shivering is defined as the fasciculation of the face, jaw, or head or muscle hyperactivity lasting longer 
than 15 seconds [5]. This phenomenon is a common occurrence observed in the postanaesthesia care unit. Previous studies have reported an incidence of 5\% to $65 \%$ after general anaesthesia and $30 \%$ to $33 \%$ after epidural procedures [6]. The overall shivering incidence in a recent meta-analysis was 34\% [4].

\section{Pathophysiology aspects}

The fundamental tremor frequency on the electromyogram in humans is typically near $200 \mathrm{~Hz}$. This basal frequency is modulated by a slow, 4-8 cycles/ min, waxing-and-waning pattern [7, 8]. In 1972 Soliman et al. found two different patterns of shivering: a tonic pattern similar to normal shivering, and a phasic wave pattern similar to a pathologic clone. In 1991, Sessler et al. published that both patterns (tonic and clonic) were thermoregulatory in volunteers $[8,9]$. The tonic pattern showed a constant sinusoide form of normal shivering and it seems to be a thermoregulatory answer to the intraoperative hypothermia. By contrast, the clonic pattern is not a normal component of thermoregulatory shivering and it seems to be specific of recovery from volatile anaesthesia. This pattern of shivering might come from the lost of inhibition produced by general anaesthesia in the control of spinal reflexes.

Shivering is elicited when the preoptic region of the hypothalamus is cooled. Efferent signals mediating shivering descend in the medial forebrain bundle. Spinal alpha motor neurons and their axons are the final common path for both coordinated movement and shivering [10]. A typical cold tremor has a specific rhythm in the form of grouped discharges in the electromyography. During continued cold stimulation of the skin or the spinal cord, motor neurons are recruited in a sequence of increasing size, starting with the small gamma motor neurons that are followed by the small tonic alpha motor neurons, and finally, the larger phasic alpha motor neurons [11, 12].

In other studies with surgical patients, not volunteers, research demonstrated a different incidence of non thermoregulatory shivering in normothermic postoperative patients [13]. A tonic stiffening pattern of muscular activity was observed as a non-temperaturedependent effect of isoflurane anaesthesia. Another observed pattern was a spontaneous electromyographic clonus that required both hypothermia and residual isoflurane end-tidal concentrations between 0.4 and $0.2 \%[8]$.

Mathew et al. describe the following shivering score which assesses the severity of shivering. 0: no shivering; 1 : mild fasciculations of face and neck and electrocardiography (ECG) disturbances in the absence of voluntary activity of the arms; 2 : visible tremor in the muscle group; 3 : gross muscular activity involving the entire body [14].

\section{Aetiology}

The combination of anaesthetic-induced thermoregulatory impairment and exposure to a cool environment makes most unwarmed surgical patients hypothermic. Shivering is usually triggered by hypothermia. However, it occurs even in normothermic patients during the perioperative period. The aetiology of shivering has not been understood sufficiently [1]. While cold induced thermoregulatory shivering remains an obvious aetiology, the phenomenon has also been attributed to numerous other causes: pain, disinhibited spine reflexes, decreased sympathetic activity, respiratory alcalosis. The conventional explanation for postanaesthetic tremor is that anaesthetic induced thermoregulatory inhibition abruptly dissipates, thus increasing the shivering threshold towards normal. Discrepancy between the persistent low body temperature and the now, near-normal threshold activates simple thermoregulatory shivering. Difficulties with this proposed explanation include the observations that tremor frequently is not observed in markedly hypothermic patients and that tremor occurs commonly in normothermic patients [15].

Perioperative hypothermia is defined as a core temperature, $33^{\circ} \mathrm{C}$ to $35^{\circ} \mathrm{C}$, while the shivering threshold in nonanaesthetized patients is $35.5^{\circ} \mathrm{C}$. Anaesthetic agents increase the heat response thresholds and decrease the cold response thresholds so that the normal interthreshold range (hypothalamic set point) is increased [16]. However, the study of Sessler et al. [8] suggested that special factors related to surgery, stress or pain, might contribute to the genesis of postoperative tremor because they failed to identify any shivering-like activity in normothermic volunteers. Pain might facilitate shivering in both postoperative patients and in women having spontaneous term labor. The mechanism of thermoregulation is tightly linked to other homeostatic systems, including the control of pain. Pain and temperature signals are transmitted along similar fibber systems that synapse in dorsal horn regions. Rostral ventromedial medulla regulates analgesia to noxious stimuli and has a thermoregulatory response to peripheral warming and cooling. One of the important functions of the rostral ventromedial medulla is to modulate the amount of pain and temperature input ascending from the spinal cord by gating the transmission of neuronal signals at the level of the dorsal horns [17]. In general, instead of the commonly held view of a single thermoregulatory integrator (i.e., the preoptic area of the hypothalamus) with multiple inputs and outputs, modern concepts include integrators for 
each thermoregulatory response. Furthermore, these integrators are distributed among numerous levels within the nervous system, with each being facilitated or inhibited by levels above and below. Therefore, shivering can be divided into two types [18]. The most common type is thermoregulatory shivering, which correlates with cutaneous vasoconstriction in response to hypothermia [13]. In contrast, approximately $15 \%$ of shivering responses is from non-thermoregulatory shivering, which is associated with cutaneous vasodilation and possibly with pain [19].

More recent studies have also reported an increased incidence of PS after remifentanil administration [20]. Remifentanil was associated with an increased incidence of postoperative shivering compared with alfentanil or fentanyl, but no significant difference was seen when compared with sufentanil [2]. In this case the mechanisms underlying are considered to include acute opioid tolerance of short-acting narcotics, which is closely related to the activation of the N-methyl-Daspartate (NMDA) receptor. Nakasuji et al. compared two doses of remifentanil and concluded that remifentanil-induced PS is not a phenomenon of intraoperative hypothermia. The higher incidence of PS with higher doses of remifentanil probably reflects acute opioid tolerance and stimulation of N-methyl-D-aspartate receptors, similar to hyperalgesia [21]. The author developed three mechanisms that may account for PS after remifentanil administration.

First, remifentanil is eliminated faster than other opioids. Opioids inhibit thermoregulatory responses; thus shivering does not occur during surgery because the threshold of shivering decreases below body temperature [22]. The threshold might return to normal immediately after discontinuance of remifentanil due to the drug's kinetics. When the threshold increases faster than the increase in body temperature during recovery from general anaesthesia, shivering is triggered.

The second mechanism is related to pain; in fact, remifentanil at high doses induced PS more frequently than at low doses. This result is in accordance with hyperalgesia caused by high doses of remifentanil in previous studies. In consequence, patients who are administered high doses of remifentanil are sensitive to shivering after sudden discontinuation [21]. Another mechanism is that shivering is a sign of opioid withdrawal caused by acute tolerance. Short-acting opioids like remifentanil could cause opioid tolerance and hyperalgesia, especially when higher doses are administered continuously. The NMDA receptors are thought to play a major role in the development of acute opioid tolerance because remifentanil-induced hyperalgesia can be prevented by low doses of ketamine, a typical NMDA antagonist. It was speculated that remifentanil stimulates the NMDA receptors and glycine as an additive in the remifentail dose could directly stimulate NMDA receptors and prophylactic ketamine was reported to be effective to prevent PS [23]. In addition, magnesium is a non-competitive NMDA receptor antagonist and intraoperative infusion of magnesium sulphate reduced PS [24]. Regarding shivering post neuroaxial anaesthesia the mechanism might be different. Both neuraxial (epidural and spinal anaesthesia) and general anaesthesia are associated with a significant incidence of shivering, and the incidence is $40 \%-60 \%$ in regional anaesthetic patients and up to $60 \%$ in general anaesthetic ones [25]. Shivering differs from general anaesthesia to neuraxial anaesthesia. General anaesthesia could impair the central thermoregulation, but spinal anaesthesia affects central and peripheral thermoregulation, by enlarging the interthreshold range via raising the sweating threshold and decreasing the vasoconstriction and shivering thresholds. The core temperature decrease will be in a plateau after 3-4 h in general anaesthesia but in the neuraxial anaesthesia there is no plateau, because in neuroaxial anaesthesia the vasoconstriction will not be evoked when the core temperature triggers the reset vasoconstriction threshold, in contrast with general anaesthesia. Thus, more heat will be lost, and more incidences will occur in neuraxial anaesthesia. For instance, the primary mechanism of perioperative hypothermia during caesarean delivery under spinal anaesthesia is because of redistribution of the intravascular volume from the core to peripheral compartment below the level of sympathectomy, predisposing the body to radiant heat loss [26]. Beside this, spinal anaesthesia itself slightly decreases the threshold-for triggering vasoconstriction and shivering above the level of the block. In addition, Doufas and colleagues reported slight decreases in thresholds during epidural anaesthesia based on an apparent increase in lower body skin temperature [27].

PS has been anecdotally observed to be frequent and severe in cannabis smokers following general anaesthesia. It has been suggested that cannabis has analgesic effects mediated via CB1 receptors in synergy with opioid and noradrenergic receptors (alpha-2 effects). Moreover, there is a suggestion that pain and temperature signals are transmitted along similar fibber systems in the dorsal horn of the spinal cord. Cannabis has been shown to interfere with both thermogenic and nonthermogenic mechanisms of PS [16].

\section{Clinical impact}

Despite the important function of shivering elevating the body's core temperature, it can be associated with important adverse effects to both healthy individuals and hospitalized patients, such as those recovering from 
anaesthesia [4]. Patients report that shivering is remarkably uncomfortable, and some even find the accompanying cold sensation worse than surgical pain. In addition, shivering might stretch surgical incisions and, as a consequence, it may intensify post surgical pain [5]. Besides the obvious discomfort in the recovery period, PS increases oxygen consumption, induce lactic acidosis, carbon dioxide production, and catecholamine release, resulting in increased cardiac output, heart rate, and arterial pressure. Shivering also occasionally impedes monitoring techniques, increases intraocular and intracranial pressures, and is especially disturbing to mothers during labor and delivery [28]. Vigorous shivering increases metabolic heat production up to $600 \%$ above basal level. Besides this, PS is believed to increase oxygen consumption by $300 \%$ to $400 \%$ and increase the risk of hypoxemia [29]. It can lead to critical ischemia in the postoperative period $[2,15]$.

Shivering may also be associated with increased adrenergic and sympathetic hyperactivity and subsequent organ dysfunction such as myocardial ischemia. In addition, shivering may cause patient discomfort and increase the likelihood of postoperative complications such as infection, pain, and bleeding [3, 8]. Shivering may be associated with delayed wound healing and increased hospital stay. These increases in metabolic requirement also might predispose to difficulties patients with existing intrapulmonary shunts, fixed cardiac output, or limited respiratory reserve. However, owing to age impairing of normal thermoregulatory control, shivering is rare in elderly patients [30]. Because shivering intensity is reduced in elderly and frail patients, it is unlikely that shivering itself provokes serious adverse outcomes in these patients [15]. Hence, PS should be avoided in patients with diminished cardiopulmonary reserve.

Regarding gender, women showed a higher incidence of shivering than men [31]. Consequently, suppressing shivering in hospitalized patients is a logical and important step in increasing comfort and reducing shivering-related complications [4].

\section{Treatment}

PS is a very common complication of surgery owing to postoperative pain and postanaesthesia hypothermia and is distressing for both patients and clinicians. Hence, effective treatment of PS has become imperative with increasing awareness of the significant benefits of maintaining euthermia intra and after anaesthesia [4]. Many therapeutic strategies for treating shivering exist and most are empiric. Unfortunately, the overall quality of the antishivering guidelines is low. While published analyses have established the efficacy of individual pharmacological and physical treatment options, few studies of combination antishivering therapy exist [3].

In addition, shivering is encountered in diverse settings and with different durations and intensities. Shivering in the postanaesthetic care area can be rather brief and justify a different algorithm than that used in the intensive care unit to treat prolonged shivering in intubated patients with intracranial hypertension or after cardiac arrest [3]. In our review we focus in postoperative shivering. The American Society of Anesthesiologists (ASA) guideline recommending forced-air warming devices and meperidine received the highest validation [3]. Consequently, we have two main strategies: pharmacological and nonpharmacological antishivering methods.

\section{Non-pharmacological therapy}

Numerous antishivering medications have been reviewed. However, the adverse effects of medications limit their utility in many clinical settings. Pharmacotherapy can interfere with clinical impact in recovery after anaesthesia, hinder neurologic examinations, and might have an effect on the hemodynamic and neurologic state. Therefore, non-pharmacologic antishivering methods are commonly used instead of medications.

These methods work by preserving or restoring the body temperature above the shivering threshold or by masking the central shivering reflex via warmed skin sensory input [18]. Active cutaneous warming (electric heating, water-circulating garments, forced-air, radiant heating) is effective in the shivering management in the perioperative and induced hypothermia settings. In contrast, evidence suggests that passive cutaneous warming (cotton blanket, elastic bandage) and body core warming (heated fluid, heated air) are of limited benefit at best [18]. Park B et al. found that active cutaneous warming was associated with the highest prevalence of positive outcomes in the clinical settings of undergoing surgery or induced hypothermia [18]. There is agreement between these results and the current American Society of Anesthesiologists Task Force on Postanesthetic Care guidelines, which recommend forced-air warming, a common method of active cutaneous warming, to reduce shivering in the perioperative setting [32]. The mechanism of active cutaneous warming by increasing body heat content, limiting heat redistribution from the core to periphery and decreasing radiant heat loss leads to effective control of thermoregulatory shivering. In addition, surface warming interferes with peripheral input from cutaneous thermoreceptors, which is responsible for approximately $20 \%$ of the shivering response. Raising the theatre temperature could prevent shivering but it is insufficient as well.

Different studies performed in caesarean delivery have utilized upper body forced-air warming preope- 
ratively with efficacy. This suggests that the patient needs to be warmed before sympathetic-mediated vasodilation and core-periphery redistribution [33, 34].

However, in other studies applying forced-air warming at the lower extremities, below the level of sympathetic inhibition, the efficacy was lower [26]. Nevertheless, the best area of application (upper or lower) is still undetermined.

The combined application of warmed i.v. fluids and forced-air warming has the potential to minimize core temperature loss. Forced-air warming warms the patient from outside in, whereas the warmed i.v. fluid may prevent a decrease in body temperature in the setting of redistribution hypothermia [26]. However, heated fluids limit convective heat loss only when large quantities are infused [8], which may explain the limited effectiveness of this method. In contrast, number of studies have found that warmed i.v. fluid as a single modality is effective in minimizing perioperative hypothermia $[35,36]$.

Airway heating with warmed and humidified air can raise nasopharyngeal, oesophageal, and core temperatures by reducing heat loss from respiratory evaporation of dry gases [37]. However, only $10 \%$ of heat loss occurs by evaporation, therefore warmed air has little effect on shivering. Despite the fact that there is no clear consensus regarding the best strategy for its prophylactic and treatment, it has been reported that PS could be prevented by warming the skin-surface and warming the administered fluid [25]. The optimal timing and duration of an intervention may be an important factor to maximize the efficacy of nonpharmacological methods. Future studies should address the optimal timing and duration of application and the extent to which antishivering medications may have additive or synergistic effects [18].

\section{Pharmacological therapy}

Many drugs have been shown to be effective on the prevention and treatment of PS, such as opioids, $\alpha_{2}$-agonists, anticholinergics, central nervous system stimulants, corticosteroids. Owing to temperature modulation, it is tightly regulated by a complex and multilevel control loop including the participation of thermal receptors, spinal cord, brain stem, anterior hypothalamus and cerebral cortex; the targeted antishivering therapy is complicated and has a wide range of medications.

Highly effective antishivering medication classes were centrally acting analgesics (tramadol), opioid receptor agonists (meperidine, fentanyl), cholinesterase inhibitors (physostigmine), and N-methyl-D-aspartate receptor antagonists (ketamine, magnesium sulfate). Meanwhile, $\alpha_{2}$-central agonists (clonidine, dexmedetomidina), and antiserotonergic (ondansetron) and antiinflammatory drugs (dexamethasone) were relatively less effective classes. This data support that medications which interfere at different levels of the thermoregulatory loop have more efficacy (opioid agonist, NMDA antagonist) than those with only one function $\left(\alpha_{2}\right.$-receptor agonist, antiserotonergic agents) or only at the peripheral level (nonsteroidal antiinflammatory agents) [18].

Park et al. in a recent meta-analysis of all randomized, double-blinded, placebo controlled antishivering medications trials identified that clonidine, meperidine, tramadol, nefopam (a centrally acting nonopioid analgesic) and ketamine were the best performing pharmacological agents [4].

However, few of them were recommended for the prevention of PS due to various side-effects. For instance, clonidine, a partial $\alpha_{2}$ adrenergic agonist, is related to bradycardia, hypotension and sedation. Ondansetron, a 5- $\mathrm{TH}_{3}$ receptor antagonist, is widely used to prevent postoperative nausea and vomiting. Nevertheless, a systematic review of antishivering medication side effects is not possible as most studies does not track side effects in a standardized way [4].

\section{Opioid receptor agonists}

Meperidine has a therapeutic effect on PS, and its mechanism is likely to be associated with the activation of $\kappa$ and $\mu$-opioid receptor, acting principally on the central nervous system. Pethidine is the only opioid that is an agonist at both the $\mu$ and $\kappa$ receptors closely related to the pathogenesis of shivering by reducing the shivering threshold and triggering decreased core temperature, which constitutes its anti-shivering effect. Meperidine is the most common intravenous drug used for treating and preventing shivering, as its equi-analgesic dose is much more efficient than other opioids such as fentanyl, alfentanil, sufentanil or morphine in preventing shivering. Taking the adverse effects into consideration, accumulating studies show that meperidine could increase the incidence of nausea and vomiting and induce respiratory depression [38].

In the systematic quality assessment of published antishivering protocols of Choi et al. a variety of individual and combination treatments were recommended, but skin warming and meperidine use were the most commonly cited strategies [3]. Regarding intrathecal via low dose intrathecal meperidine as an adjuvant for spinal anaesthesia could effectively prevent shivering and reduce need for rescue analgesics, yet still might increase the risk of nausea and vomiting [39]. Chiang et al. studied the relationship between PS and free flap failure owing to postoperative compromise, and demonstrated that an optimal dose of meperidine could prevent PS, which is shown to be associated with a decrease in the incidence of the early post-surgical re-exploration rate of these free flaps related to circulatory compromise [40]. 
Tramadol is a synthetic opioid that acts at multiple sites. It is a weak $\mu$-opioid receptor agonist and has minimal activity at $\kappa$ - or $\sigma$-receptors. It is also a partial inhibitor of norepinephrine and 5-hydroxytryptamine (5HT). Tramadol also reportedly inhibits the N-methylD-aspartic acid (NMDA) receptor at clinically relevant concentrations. Different studies report its efficacy. Seifi et al. also reported that pethidine $0.5 \mathrm{mg} / \mathrm{kg}$ is as effective as tramadol $1 \mathrm{mg} / \mathrm{kg}$ for PS during the first 15 min after injection, while tramadol is associated with less side effects [41].

Heid et al. reported that the administration of $2 \mathrm{mg} /$ $\mathrm{kg}$ tramadol reduced the incidence and extent of PS after lumbar disc surgery under remifentanil isoflurane general anaesthesia [42]. Mohta et al. also reported that tramadol $2 \mathrm{mg} / \mathrm{kg}$ provided an effective combination of anti-PS activity and analgesia without excessive sedation [43]. Nakagawa et al. showed that the administration of tramadol $(3 \mathrm{mg} / \mathrm{kg})$ at induction of anaesthesia significantly reduced the incidence of PS independently of remifentanil concentration used intraoperatively [44]. Ketamine is a competitive antagonist at the NMDA receptor, suggesting that the antishivering effect of tramadol might be mediated by the NMDA receptor [44].

\section{Antiserotonergic agents}

Opioid and non-opioid drugs are often used to treat postoperative shivering, but they have potential side effects, including hypotension, hypertension, sedation, respiratory depression, nausea and vomiting. More recently, $5-\mathrm{HT}_{3}$ receptor antagonists have emerged as means of preventing postoperative shivering. According to meta-analysis by Zhoy $\mathrm{C}, 5-\mathrm{HT}_{3}$ receptor antagonists appear to prevent postoperative shivering, with a broadly comparable efficacy to meperidine [45].

The preoptic area of the hypothalamus releases 5$\mathrm{HT}_{3}$ to activate heat production pathways, and thus increase body temperature. $5-\mathrm{HT}_{3}$ antagonists may prevent postoperative shivering by inhibiting reuptake of 5-HT in the preoptic area.

$5-\mathrm{HT}_{3}$ antagonists effectively prevent postoperative shivering after general anaesthesia and spinal anaesthesia [45].

Ondansetron, a 5- $\mathrm{HT}_{3}$ (serotonin) antagonist, is generally used as an antiemetic but its efficiency and safety in the prevention of PS remains controversial. Serotonin system plays an important role in the thermoregulation. The mechanisms of ondansetron on PS may be related to a central mechanism of the inhibition of 5-HT reuptake on the preoptic anterior hypothalamic region. Both $4 \mathrm{mg}$ and $8 \mathrm{mg}$ of ondansetron at the end of surgery could reduce the risk of PS significantly [46]. Ondansetron and meperidine have similar effects on the prevention of PS without significant association of ondansetron with bradycardia. In contrast, ondansetron was significantly associated with a lower risk of hypotension. According to Li M et al., meta-analysis treatment with ondansetron is safe, and may reduce PS. This finding encourages the use of ondansetron to prevent PS [47].

Palonosetron is a new generation of a $5-\mathrm{HT}_{3}$ antagonist which did not influence perioperative hypothermia or PAS [48].

\section{$N$-methyl-D-aspartate receptor antagonist}

Ketamine is a noncompetitive NMDA receptor antagonist and it has a central sympathomimetic effect by inhibition of postganglionic NE uptake. One of its effects is to decrease core-to-peripheral heat distribution.

Nakasuji et al. demonstrated that low-dose ketamine infusion (blood concentration around $100 \mathrm{ng} / \mathrm{mL}$ ) during surgery reduces the incidence of postoperative shivering after remifentanil-based anaesthesia. They concluded that the preventive effect of ketamine on the development of remifentanil-induced shivering was through a NMDA receptor antagonism during anaesthesia. Nevertheless, the exact underlying mechanism for this finding (residual sedative and analgesic effects after discontinuation or stimulation of the NMDA receptors) remains to be determined. Nakasuji et al. consider the stimulation of the NMDA receptors is the more likely underlying mechanism of remifentanilinduced PS rather than residual sedative and analgesic effects [49].

Magnesium sulfate is a naturally occurring calcium antagonist and a non-competitive antagonist of $\mathrm{N}$ methyl-D-aspartate (NMDA) receptors. The drug not only exerts a central effect but is also a mild muscle relaxant and thus may simultaneously reduce the gain of shivering (incremental shivering intensity with progressing hypothermia) [24].

Intraoperative infusion of magnesium sulphate reduced PS. Magnesium is an effective treatment for postoperative shivering. It reduces the shivering threshold by only a few tenths of a degree Celsius; however, many postoperative patients have core temperatures only slightly below the normal shivering threshold. For this reason, magnesium may be sufficient to attenuate postoperative shivering [24].

Ryu et al. demonstrated that magnesium (bolus 50 $\mathrm{mg} / \mathrm{kg}$ i.v. and $15 \mathrm{mg} / \mathrm{kg} / \mathrm{h}$ continuous infusion) during a propofol-remifentanil-based total intravenous anaesthesia reduces postoperative shivering and PONV [50].

\section{$\alpha_{2}$-receptor agonist}

Alpha $_{2}$ adrenergic agonist receptors, which can lead to reduced sympathetic activity and central regulation of vasoconstrictor tone, are a group of drugs that have been used to try to prevent postoperative shivering. According to the Cochrane review, there is evidence 
that clonidine and dexmedetomidine can reduce postoperative shivering, but patients given dexmedetomidine may be more sedated. However, the quality of this evidence is very low [51]. The doses, methods and time of administration have a wide range of possibilities: orally or intravenous, intraoperatively or preoperatively.

The prophylactic administration of intravenous dexmedetomidine reduces the incidence of postanaesthetic shivering in patients undergoing general anaesthesia [52].

Liu ZX et al. conclude in their meta-analysis that dexmedetomidine shows superiority over placebo in the prevention of postoperative shivering, but not over other anti-shivering agents. The beneficial effect can be achieved through both intravenous and epidural injection [53]. Nevertheless, the time interval between the last administration and the end of surgery should be less than two hours, which is about the half-life of dexmedetomidine. Regarding to the doses $1 \mathrm{mg} / \mathrm{kg}$ bolus is the most commonly used, $0.5 \mathrm{mg} / \mathrm{kg}$ i.v. might be sufficient for a preventive effect.

Dexmedetomidine suppresses the spontaneous firing rate of neurons, decreases the central thermosensitivity, and finally reduces the vasoconstriction and shivering thresholds. Undesirable effects are sedation, bradycardia, hypotension and a dry mouth.

Nevertheless, due to its relatively high price and potential side effects, the use of dexmedetomidine is not recommended solely for the purpose of preventing postoperative shivering [53].

\section{Other drugs}

Other drugs aimed at the treatment and prophylactic of PS have been found. Physostigmine inhibits PAS through cholinergic system, but it can also cause nausea and vomiting, increased heart rate and blood pressure. Doxapram, used as a stimulant in respiratory failure, had been proven to be effective on PS, but accompanied with a distinct side effect on hemodynamics. Hydrocortisone (1-2 mgkg-1 i.v.) provides effective prophylaxis against postoperative shivering in patients undergoing day care knee arthroscopy under general anaesthesia [54]. Nefopam, a centrally acting analgesic inhibiting synaptosomal reuptake of several neurotransmitters: dopamine, NE and serotonin, is one of the most studied effective antishivering drugs [4].

Prophylactic administration of parecoxib produces dual effects on antishivering and postoperative analgesia. This implies that cyclooxygenase 2-prostaglandin $\mathrm{E}_{2}$ pathways may be involved in the regulation of shivering [55].

Amino acid (AA) infusion is sometimes selected to avoid hypothermia during general anaesthesia. Aoki Y et al. showed that AA infusions administered in the perioperative period led to a small increase in the patient body temperature, a decrease in the frequency of shi- vering, a decrease in the time to extubation, and a decrease in the duration of hospitalization [56].

In summary, a final conclusion about the optimal antishivering medication is difficult to establish. Numerous studies have tested the efficacy of a large variety of interventions that are thought to prevent shivering in normothermic or hypothermic surgical patients. The relative efficacy of these interventions, however, remains unclear. Clonidine, meperidine, tramadol and ketamine are the most studied and are efficacious medications. Park SM et al. do not recommend either the combination of medications given the paucity of available data (ketamine + midazolam or ketamine + naloxone). Beside this, there is a wide heterogeneity regarding to doses, via and timing of administration [4].

The potential additive or synergistic effects of pharmacotherapy and nonpharmacological methods were studied by Kimberger et al., who found an additive effect between active cutaneous warming and i.v. meperidine [57]. It is, therefore, encouraging that some simple and inexpensive interventions are effective in the treatment of this adverse effect of anaesthesia and surgery.

\section{Conclusion}

Postanaesthetic shivering is a common complication after anaesthesia which is remarkably uncomfortable to patients and it might lead to severe complications due to the augmentation of oxygen consumption evoked.

Postoperative shivering can be either thermogenic (associated with hypothermia) or nonthermogenic (associated with pain modulation, surgical stress, etc.).

Effective prevention and treatment of shivering has become an essential step in increasing postoperative comfort and reducing shivering related complications.

Firstly, it is essential to keep the patient normothermic with non-pharmacological methods: warming the skin-surface and warming the administered fluid. Secondly, many drugs have been shown to be effective in the prophylaxis of PS. Despite the lack of high-quality evidence, control of PS is possible and clinically effective with simple pharmacological interventions combined with non-pharmacological methods.

However, to be consistent with the most up-to-date, evidence-based practice, future antishivering treatment protocols should optimize methodological rigor and transparency.

\section{Conflict of interest}

Nothing to declare 


\section{References}

1. Eberhart LH, Döderlein F, Eisenhardt G, Kranke P, Sessler DI, Torossian A, et al. Independent risk factors for postoperative shivering. Anesth Analg 2005; 101: 1849-1857. doi: 10.1213/ 01.ANE.0000184128.41795.FE

2. Hoshijima H, Takeuchi R, Kuratani N, Nishizawa S, Denawa Y, Shiga $\mathrm{T}$, et al. Incidence of postoperative shivering comparing remifentanil with other opioids: a meta-analysis. J Clin Anesth 2016; 32: 300-312. doi: 10.1016/j.jclinane.2015.08.017

3. Choi KE, Park B, Moheet AM, Rosen A, Lahiri S, Rosengart A. Systematic Quality Assessment of Published Antishivering Protocols. Anesth Analg 2017; 124: 1539-1546. doi: 10.1213/ ANE.0000000000001571

4. Park SM, Mangat HS, Berger K, Rosengart AJ. Efficacy spectrum of antishivering medications: Meta-analysis of randomized controlled trials. Crit Care Med 2012; 40: 3070-3082. doi: 10.1097/CCM.0b013e31825b931e

5. Crossley AW. Six Months of shivering in a district general hospital. Anaesthesia 1992; 47: 845-848. doi: 10.1111/j.1365-2044. 1992.tb03143.x

6. Buggy DJ, Crossley AW. Thermoregulation, mild perioperative hypothermia and postanaesthetic shivering. Br J Anaesth 2000; 84: 615-628

7. Israel DJ, Pozos RS. Synchronized slow-amplitude modulations in the electromyograms of shivering muscles. J Appl Physiol 1989; 66: 2358-2363. doi: 10.1152/jappl.1989.66.5.2358

8. Sessler DI, Rubinstein EH, Moayeri A. Physiologic responses to mild perianesthetic hypothermia in humans. Anesthesiology 1991; 75: 594-610

9. Soliman MG, Gillies DM. Muscular hyperactivity after general anaesthesia. Can Anaesth Soc J 1972; 19: 529-535

10. Henneman E. Organization of the motoneuron pool: The size principle. In: Mountcastle VB, editor. Medical Physiology. $14^{\text {th }}$ ed St. Louis: CV Mosby; 1980: 718-741

11. Klussmann FW, Spaan G, Stelter HJ, Rau B. Synchronization of motor neuron discharges during shivering. Pflügers Arch 1969; 312: R108

12. Lupandin IV. Regulation of the function of gamma- and alphamotor neurons of antagonist muscles during cold tremor in the cat. Neirofiziologiia 1983; 15: 242-248

13. Horn EP, Sessler DI, Standl T, Schroeder F, Bartz HJ, Beyer JC, et al. Non-thermoregulatory shivering in patients recovering from isoflurane or desflurane anesthesia. Anesthesiology 1998; 89: $878-886$

14. Mathews A, Al Mulla A, Varghese PK, Radim K, Mumtaz S. Postanaesthetic shivering - a new look at tramadol. Anaesthesia 2002; 57: 394-398. doi: 10.1046/j.1365-2044.2002.2457_3.x

15. De Witte J, Sessler DI. Perioperative shivering: Physiology and pharmacology. Anesthesiology 2002; 96: 467-484. doi: 10.1097/ 00000542-200202000-00036

16. Sankar-Maharaj S, Chen D, Hariharan S. Postoperative shivering among cannabis users at a public hospital in Trinidad, West Indies. J Perianesth Nurs 2018; 33: 37-44. doi: 10.1016/j.jopan. 2016.03 .010

17. Grahn DA, Heller HC. Activity of most rostral ventromedial medulla neurons reflect EEG/EMG pattern changes. Am J Physiol 1989; 257: R1496-1505. doi: 10.1152/ajpregu.1989.257.6. R 1496

18. Park B, Lee T, Berger K, Park SM, Choi KE, Goodsell TM, et al. Efficacy of Nonpharmacological Antishivering Interventions: A Systematic Analysis. Crit Care Med 2015; 43: 1757-1766. doi: 10.1097/CCM.0000000000001014
19. Horn EP, Schroeder F, Wilhelm S, Sessler DI, Standl T, von dem Busche K, et al. Postoperative pain facilitates nonthermoregulatory tremor. Anesthesiology 1999; 91: 979-984

20. Röhm KD, Riechmann J, Boldt J, Suttner SW, Piper SN. Total intravenous anesthesia with propofol and remifentanil is associated with a nearly twofold higher incidence in postanesthetic shivering than desflurane-fentanyl anesthesia. Med Sci Monit 2006; 12: CR452-456

21. Nakasuji M, Nakamura M, Imanaka N, Tanaka M, Nomura M, Suh SH. Intraoperative high-dose remifentanil increases postanaesthetic shivering. Br J Anaesth 2010; 105: 162-167. doi: $10.1093 / \mathrm{bja} / \mathrm{aeq} 121$

22. Kurz A, Go JC, Sessler DI, Kaer K, Larson M, Bjorksten AR. Alfentanil slightly increases the sweating threshold and markedly reduces the vasoconstriction and shivering thresholds. Anesthesiology 1995; 83: 293-299. doi: 10.1097/00000542199508000-00009

23. Dal D, Kose A, Honca M, Akinci SB, Basgul E, Aypar U. Efficacy of prophylactic ketamine in preventing postoperative shivering. Br J Anaesth 2005; 95: 189-192. doi: 10.1093/bja/aei148

24. Wadhwa A, Sengupta P, Durrani J, Akça O, Lenhardt R, Sessler DI, et al. Magnesium sulphate only slightly reduces the shivering threshold in humans. Br J Anaesth 2005; 94: 756-762. doi: 10.1093/bja/aei105

25. Tie HT, Su GZ, He K, Liang SR, Yuan HW, Mou JH. Efficacy and safety of ondansetron in preventing postanesthesia shivering: a meta-analysis of randomized controlled trials. BMC Anesthesiol 2014; 14: 12. doi: 10.1186/1471-2253-14-12

26. Cobb B, Cho Y, Hilton G, Ting V, Carvalho B. Active Warming Utilizing Combined IV Fluid and Forced-Air Warming Decreases Hypothermia and Improves Maternal Comfort During Cesarean Delivery: A Randomized Control Trial. Anesth Analg 2016; 122: 1490-1497. doi: 10.1213/ANE.0000000000001181

27. Doufas AG, Morioka N, Maghoub AN, Mascha E, Sessler DI. Lower-body warming mimics the normal epidural-induced reduction in the shivering threshold. Anesth Analg 2008; 106: 252-256. doi: 10.1213/01 ane.0000287814.78990.4e

28. Ostheimer GW, Datta S. Observations in the postpartum recovery room after various local anesthetic techniques. Reg Anesth Pain Med 1981; 6: 13-17

29. Sharkey A, Gulden RH, Lipton JM, Giesecke AH. Effect of radiant heat on the metabolic cost of postoperative shivering. Br J Anaesth 1993; 70: 449-450. doi: 10.1093/bja/70.4.449

30. Frank SM, Fleisher LA, Olson KF, Gorman RB, Higgins MS, Breslow MJ, et al. Multivariate determinants of early postoperative oxygen consumption in elderly patients: effects of shivering, body temperature, and gender. Anesthesiology 1995; 83: 241-249

31. Conti D, Ballo P, Boccalini R, Boccherini A, Cantini S, Venni A, et al. The effect of patient sex on the incidence of early adverse effects in a population of elderly patients. Anaesth Intensive Care 2014; 42: 455-459

32. Apfelbaum JL, Silverstein JH, Chung FF, Connis RT, Fillmore RB, Hunt SE, et al.; American Society of Anesthesiologists Task Force on Postanesthetic Care. guidelines for postanesthetic care: an updated report by the American Society of Anesthesiologists Task Force on Postanesthetic Care. Anesthesiology 2013; 118 : 291-307. doi: 10.1097/ALN.0b013e31827773e9

33. Chung SH, Lee BS, Yang HJ, Kweon KS, Kim HH, Song J, et al. Effect of preoperative warming during cesarean section under spinal anesthesia. Korean J Anesthesiol 2012; 62: 454-460. doi: $10.4097 / \mathrm{kjae} .2012 .62 .5 .454$ 
34. Horn EP, Schroeder F, Gottschalk A, Sessler DI, Hiltmeyer N, Standl T, et al. Active warming during cesarean delivery. Anesth Analg 2002; 94: 409-414. doi: 10.1213/00000539-20020200000034

35. Woolnough M, Allam J, Hemingway C, Cox M, Yentis SM. Intra-operative fluid warming in elective caesarean section: a blinded randomised controlled trial. Int J Obstet Anesth 2009; 18: 346-351. doi: 10.1016/j.ijoa.2009.02.009

36. Goyal P, Kundra S, Sharma S, Grewal A, Kaul TK, Singh MR. Efficacy of intravenous fluid warming for maintenance of core temperature during lower segment cesarean section under spinal anesthesia. J Obstet Anaesth Crit Care 2011; 1: 73-77. doi: 10.4103/2249-4472.93990

37. Forstot RM. The etiology and management of inadvertent perioperative hypothermia. J Clin Anesth 1995; 7: 657-674. doi: 10.1016/0952-8180(95)00099-2

38. Dabir S, Jahandideh M, Abbasinazari M, Kouzekanani H, Parsa $\mathrm{T}$, Radpay B. The efficacy of a single dose of pethidine, fentanyl and morphine in treating postanesthesia shivering. Pak J Pharm Sci 2011; 24: 513-517

39. Lin YC, Chen CY, Liao YM, Liao AH, Lin PC, Chang CC. Preventing shivering with adjuvant low dose intrathecal meperidine: A meta-analysis of randomized controlled trials with trial sequential analysis. Sci Rep 2017; 7: 15323. doi: 10.1038/s41598-017-14917-5

40. Chiang MH, Chung KC, Syue YJ, Chia-Shen Yang J, Chien CY, Kuo YR. The role of meperidine in reduction of postanesthetic shivering and its possible impact on flap outcomes. Microsurgery 2014; 34: 106-111. doi: 10.1002/micr.22133

41. Seifi A, Avestimehr S, Mowla A, KamaliPour H. A Comparative Study of the effect of tramadol and pethidine on postoperative shivering. Int J Anesth 2007; 16: 1-6

42. Heid F, Grimm U, Roth W, Piepho T, Kerz T, Jage J. Intraoperative tramadol reduces shivering but not pain after remifentanilisoflurane general anaesthesia. A placebo-controlled, doubleblind trial. Eur J Anaesthesiol 2008; 25: 468-472. doi: 10.1017/ S0265021508003645

43. Mohta M, Kumari N, Tyagi A, Sethi AK, Agarwal D, Singh M. Tramadol for prevention of postanaesthetic shivering: a randomised double-blind comparison with pethidine. Anaesthesia 2009; 64: 141-146. doi: 10.1111/j.1365-2044.2008.05711.x

44. Nakagawa T, Hashimoto M, Hashimoto Y, Shirozu K, Hoka S. The effects of tramadol on postoperative shivering after sevoflurane and remifentanil anesthesia. BMC Anesthesiol 2017; 17: 1. doi: 10.1186/s12871-016-0295-x

45. Zhou C, Zhu Y, Liu Z, Ruan L. 5-HT3 receptor antagonists for the prevention of postoperative shivering: a meta-analysis. J Int Med Res 2016; 44: 1174-1181. doi: 10.1177/ 0300060516668776
46. He K, Zhao H, Zhou HC. Efficiency and safety of ondansetron in preventing postanaesthesia shivering. Ann R Coll Surg Engl 2016; 98: 358-366. doi: 10.1308/rcsann.2016.0152

47. Li M, Hu X, Tan Y, Yang B, Li K, Tang Z . Meta-analysis of randomized controlled trials on the efficacy and safety of ondansetron in preventing postanesthesia shivering. Int J Surg 2016; 35: 34-43. doi: 10.1016/j.ijsu.2016.09.009

48. Jo YY, Kim YB, Lee D, Chang YJ, Kwak HJ. Implications of palonosetron in elderly patients undergoing laparoscopic cholecystectomy with respect to its anti-shivering effect. Aging Clin Exp Res 2016; 28: 83-88. doi: 10.1007/s40520-015-0373-9

49. Nakasuji M, Nakamura M, Imanaka N, Tanaka M, Nomura M, Suh SH. An intraoperative small dose of ketamine prevents remifentanil-induced postanesthetic shivering. Anesth Analg 2011; 113: 484-487. doi: 10.1213/ANE.0b013e318224ac4e

50. Ryu JH, Kang MH, Park KS, Do SH. Effects of magnesium sulphate on intraoperative anaesthetic requirements and postoperative analgesia in gynaecology patients receiving total intravenous anaesthesia. Br J Anaesth 2008; 100: 397-403. doi: 10.1093/bja/aem407

51. Lewis SR, Nicholson A, Smith AF, Alderson P. Alpha-2 adrenergic agonists for the prevention of shivering following general anaesthesia. Cochrane Database Syst Rev 2015, (8). CD011107. doi: 10.1002/14651858.CD011107.pub2

52. Hoffman J, Hamner C. Effectiveness of dexmedetomidine use in general anesthesia to prevent postoperative shivering: a systematic review. JBI Database System Rev Implement Rep 2016; 13: 287-313. doi: 10.11124/jbisrir-2015-2257

53. Liu ZX, Xu FY, Liang X, Zhou M, Wu L, Wu JR, et al. Efficacy of dexmedetomidine on postoperative shivering: a meta-analysis of clinical trials. Can J Anaesth 2015; 62: 816-829. doi: 10.1007/ s12630-015-0368-1

54. Pawar MS, Suri N, Kaul N, Lad S, Khan RM. Hydrocortisone reduces postoperative shivering following day care knee arthroscopy. Can J Anaesth 2011; 58: 924-928. doi: 10.1007/ s12630-011-9566-7

55. Shen H, Chen Y, Lu KZ, Chen J. Parecoxib for the prevention of shivering after general anesthesia. J Surg Res 2015; 197: 139-144. doi: 10.1016/j.jss.2015.03.011

56. Aoki Y, Aoshima Y, Atsumi K, Kaminaka R, Nakau R, Yanagida $\mathrm{K}$, et al. Perioperative Amino Acid Infusion for Preventing Hypothermia and Improving Clinical Outcomes During Surgery Under General Anesthesia: A Systematic Review and Metaanalysis. Anesth Analg 2017; 125: 793-802. doi: 10.1213/ANE. 0000000000002278

57. Kimberger O, Ali SZ, Markstaller M Zmoos S, Lauber R, Hunkeler C, Kurz A. Meperidine and skin surface warming additively reduce the shivering threshold: a volunteer study. Crit Care 2007; 11: R29. doi: $10.1186 / \operatorname{cc} 5709$ 